\title{
A Modified Activated Sludge Model No.3 (ASM3) for Membrane Bioreactor (MBR) with an Emphasis for Solids Hydrolysis
}

\author{
Xinyue Jiang*, Bin Xu \\ School of Environmental Engineering and Science, Yangzhou University, Yangzhou. People's Republic of China
}

\begin{abstract}
The previously assumed "inert" organics measured by respirometric method has been reported to be hydrolysable under long sludge retention time (SRT) configuration such as membrane bioreactor(MBR). The sludge production under long SRT has also shown to be lower than the standard activated sludge model (ASM) prediction. The hydrolysis of "inert" organics can provide the extra carbon source for denitrification. The current modeling approach has not yet included this aspect. In this study, a modified ASM3 was developed to account for the hydrolysis of "inert" organics and subsequent effect on the denitrification process under long SRT.
\end{abstract}

\section{Introduction}

The ASM family (ASM1, 2, 2D, 3) is designed for conventional activated sludge (CAS) wastewater treatment system with lower and upper SRT limit of 3 and 30 days[1]. The MBR usually features high SRT, high mixed liquor concentration[2]. Therefore the migration of ASM developed for CAS process to MBR system usually requires the modification of the original model. The modification usually related to the change of parameter values or the model framework by adding more processes and state varibles[3].

The high SRT in MBR also challenged the conventional respirometric method in determining the slowly biodegradable $\operatorname{COD}\left(X_{S}\right)$ and inert $\operatorname{COD}\left(X_{I}\right)$ [4]. The respirometric method was usually carried out in short term; therefore a large part of slowly hydrolysable organics $\left(X_{S H}\right)$ was included in the $X_{I}$ fraction. Under long SRT, a significant part of the "inert" organics $\left(X_{I}\right)$ can actually be hydrolyzed[3]. The application of ASM originally developed for CAS in MBR results in the overestimation of sludge production.

The modified ASMs for MBR are mainly for the estimation of sludge production[5]. It is not clear how the hydrolysis of "inert" organics $\left(X_{I}\right)$ affect the denitrification process. The shortage of readily biodegradable COD $\left(S_{S}\right)$ is usually a major limitation of the denitrification step in biological nutrient removal (BNR) process. Theoretically, the extra $S_{S}$ from the "inert" organics hydrolysis can increase the carbon source available for denitrification. In this study, a modified ASM3 was developed to account for the hydrolysis of $X_{I}$ and subsequent effect on the denitrification process under long SRT. The ASM3 was chosen because it includes a storage process, which was commonly observed in MBR with post-denitrification configuration[6][7], in which the stored carbon source $\left(X_{S T O}\right)$ was assumed to be the major electron donor for denitrification.

\section{Model development and implementation}

\subsection{The hydrolysis of slowly hydrolysable solids $\left(X_{S H}\right)$}

A new state variable $X_{S H}$ was introduced that included the $X_{I}$ fraction and the inert solids from endogenous decay $\left(X_{P}\right)$. The hydrolysis of was assumed to be first order kinetics following recommendation from Lubello et al. [5]:

$$
\frac{d X_{S H}}{d t}=-k_{S H} X_{S H}
$$

Where, $k_{S H}$ was the hydrolysis rate, with a default value of $0.012 \mathrm{~d}^{-1}$.

A complete stoichiometric matrix and kinetic rates of the modified ASM3 model could be found in Table. 1 and Table.2. The definition of symbols and parameter values could be found in [1]. 
Table.1 Stoichiometric matrix of the modified ASM3 model

\begin{tabular}{|c|c|c|c|c|c|c|c|c|c|c|c|c|}
\hline & Components & 1 & 2 & 3 & 4 & 5 & 6 & 7 & 8 & 9 & 10 & 11 \\
\hline \multicolumn{2}{|c|}{ Process } & $S_{\mathrm{O} 2}$ & $S_{I}$ & $S S$ & $S_{N H 4}$ & $S_{N O X}$ & $S_{A L K}$ & $X_{S H}$ & $X_{S}$ & $X_{H}$ & $X_{A}$ & $X_{S T O}$ \\
\hline 1 & $\begin{array}{l}\text { Hydrolysis } \\
\text { of } X_{S}\end{array}$ & & $f_{S I}$ & $1-f_{S I}$ & $\begin{array}{l}i_{N, X S}-i_{N, S S}(1- \\
\left.f_{S I}\right)-f_{S I} i_{N, S I}\end{array}$ & & {$\left[i_{N, X S}-i_{N, S S}\left(1-f_{S I}\right)-f_{S I} i_{N, S I}\right] / 14$} & & -1 & & & \\
\hline 2 & $\begin{array}{l}\text { Hydrolysis } \\
\text { of } X_{S H}\end{array}$ & & $f_{S I}$ & $1-f_{S I}$ & $\begin{array}{l}i_{N, X S}-i_{N, S S}(1- \\
\left.f_{S I}\right)-f_{S I} i_{N, S I}\end{array}$ & & {$\left[i_{N, X S}-i_{N, S S}\left(1-f_{S I}\right)-f_{S I} i_{N, S I}\right] / 14$} & -1 & & & & \\
\hline 3 & $\begin{array}{l}\text { Aerobic } \\
\text { storage of } S_{S}\end{array}$ & $Y_{S T O, O 2-1}$ & & -1 & $i_{N, S S}$ & & $i_{N, S S} / 14$ & & & & & $Y_{S T O, O 2}$ \\
\hline 4 & $\begin{array}{l}\text { Anoxic } \\
\text { storage of } S_{S}\end{array}$ & & & -1 & $i_{N, S S}$ & $\begin{array}{c}\left(Y_{S T O, N O X^{-1}}\right) / \\
2.86\end{array}$ & {$\left[i_{N, S S^{-}}\left(Y_{S T O, N O X^{-}}-1\right) / 2.86\right] / 14$} & & & & & $Y_{S T O, N O X}$ \\
\hline 5 & $\begin{array}{l}\text { Aerobic } \\
\text { growth of } X_{H}\end{array}$ & $1-1 / Y_{H, O 2}$ & & & $-i_{N, B M}$ & & $-i_{N, B M} / 14$ & & & 1 & & $-1 / Y_{H, O 2}$ \\
\hline 6 & $\begin{array}{l}\text { Anoxic } \\
\text { growth of } X_{H}\end{array}$ & & & & $-i_{N, B M}$ & $\begin{array}{c}\left(1-1 / Y_{H, N O X}\right) \\
/ 2.86 \\
\end{array}$ & {$\left[-i_{N, B M^{-}}\left(Y_{H, N O X^{-}} 1\right) / 2.86\right] / 14$} & & & 1 & & $-1 / Y_{H, N O X}$ \\
\hline 7 & $\begin{array}{l}\text { Aerobic } \\
\text { endog. } \\
\text { Respiration } \\
\text { of } X_{H}\end{array}$ & $f_{S H^{-}}-1$ & & & $i_{N, B M}-f_{S H} i_{N, X S H}$ & & $\left(-i_{N, B M}-f_{S H} i_{N, X S H}\right) / 14$ & $f_{S H}$ & & -1 & & \\
\hline 8 & $\begin{array}{l}\text { Anoxic } \\
\text { endog. } \\
\text { Respiration } \\
\text { of } X_{H}\end{array}$ & & & & $i_{N, B M}-f_{S H} i_{N, X S H}$ & $\left(f_{S H^{-}}-1\right) / 2.86$ & {$\left[i_{N, B M}-f_{S H^{\prime}, X S H^{-}}\left(f_{S H^{-}} 1\right) / 2.86\right] / 14$} & $f_{S H}$ & & -1 & & \\
\hline 9 & $\begin{array}{l}\text { Aerobic } \\
\text { respiration } \\
\text { of } X_{S T O}\end{array}$ & -1 & & & & & & & & & & -1 \\
\hline 10 & $\begin{array}{l}\text { Anoxic } \\
\text { respiration } \\
\text { of } X_{S T O} \\
\end{array}$ & & & & & $-1 / 2.86$ & $1 / 2.86 / 14$ & & & & & -1 \\
\hline 11 & $\begin{array}{l}\text { Aerobic } \\
\text { growth of } X_{A}\end{array}$ & $1-4.57 / Y_{A}$ & & & $-i_{N, B M}-1 / Y_{A}$ & $1 / Y_{A}$ & $-1 / 7 Y_{A^{-}} i_{N, B M} / 14$ & & & & 1 & \\
\hline 12 & $\begin{array}{l}\text { Aerobic } \\
\text { endog. } \\
\text { Respiration } \\
\text { of } X_{A}\end{array}$ & $f_{S H^{-}}-1$ & & & $i_{N, B M}-f_{S H} i_{N, X S H}$ & & $\left(i_{N, B M}-f_{S H} i_{N, X S H}\right) / 14$ & $f_{S H}$ & & & -1 & \\
\hline 13 & $\begin{array}{l}\text { Anoxic } \\
\text { endog. } \\
\text { Respiration } \\
\text { of } X_{A}\end{array}$ & & & & $i_{N, B M}-f_{S H} i_{N, X S H}$ & $\left(f_{S H^{-}}-1\right) / 2.86$ & $\begin{array}{c}{\left[i_{N, B M}-f_{S H} i_{N, X S H}\right.} \\
\left.-\left(f_{S H^{-}}-1\right) / 2.86\right] / 14\end{array}$ & $f_{S H}$ & & & -1 & \\
\hline
\end{tabular}


Table 2. Kinetic rates for the modified ASM3 model

\begin{tabular}{|c|c|c|}
\hline $\mathrm{j}$ & Processes & Process rate $\mathrm{Rj}$ \\
\hline 1 & Hydrolysis of $X_{S}$ & $R_{1}=k_{H} \frac{X_{S} / X_{H}}{K_{X}+X_{S} / X_{H}} X_{H}$ \\
\hline 2 & Hydrolysis of $X_{S H}$ & $R_{2}=k_{S H} X_{S H}$ \\
\hline 3 & Aerobic storage of $S_{S}$ & $R_{3}=k_{S T O} \frac{S_{O_{2}}}{K_{O_{2}}+S_{O_{2}}} \frac{S_{S}}{K_{S}+S_{S}} X_{H}$ \\
\hline 4 & Anoxic storage of $S_{S}$ & $R_{4}=k_{S T O} \eta_{N O_{X}} \frac{K_{O_{2}}}{K_{O_{2}}+S_{O_{2}}} \frac{S_{N O_{X}}}{K_{N O_{X}}+S_{N O_{X}}} \frac{S_{S}}{K_{S}+S_{S}} X_{H}$ \\
\hline 5 & Aerobic growth of $X_{H}$ & $R_{5}=\mu_{H} \frac{S_{O_{2}}}{K_{O_{2}}+S_{O_{2}}} \frac{S_{N H}}{K_{N H}+S_{N H}} \frac{S_{A L K}}{K_{A L K}+S_{A L K}} \frac{X_{S T O} / X_{H}}{K_{S T O}+\left(X_{S T O} / X_{H}\right)} X_{H}$ \\
\hline 6 & Anoxic growth of $X_{H}$ & $R_{6}=\mu_{H} \eta_{N O_{X}} \frac{K_{O_{2}}}{K_{O_{2}}+S_{O_{2}}} \frac{S_{N H}}{K_{N H}+S_{N H}} \frac{S_{A L K}}{K_{A L K}+S_{A L K}} \frac{X_{S T O} / X_{H}}{K_{S T O}+\left(X_{S T O} / X_{H}\right)} X_{H}$ \\
\hline 7 & Aerobic endog. Respiration of $X_{H}$ & $R_{7}=b_{H, O_{2}} \frac{S_{O_{2}}}{K_{O_{2}}+S_{O_{2}}} X_{H}$ \\
\hline 8 & Anoxic endog. Respiration of $X_{H}$ & $R_{8}=b_{H, N O_{X}} \frac{K_{O_{2}}}{K_{O_{2}}+S_{O_{2}}} \frac{S_{N O_{X}}}{K_{N O_{X}}+S_{N O_{X}}} X_{H}$ \\
\hline 9 & Aerobic respiration of $X_{S T O}$ & $R_{9}=b_{H, O_{2}} \frac{S_{O_{2}}}{K_{O_{2}}+S_{O_{2}}} X_{S T O}$ \\
\hline 10 & Anoxic respiration of $X_{S T O}$ & $R_{10}=b_{H, N O_{X}} \frac{K_{O_{2}}}{K_{O_{2}}+S_{O_{2}}} \frac{S_{N O_{X}}}{K_{N O_{X}}+S_{N O_{X}}} X_{S T O}$ \\
\hline 11 & Aerobic growth of $X_{A}$ & $R_{11}=\mu_{A} \frac{S_{O_{2}}}{K_{A, O_{2}}+S_{O_{2}}} \frac{S_{N H}}{K_{A, N H}+S_{N H}} \frac{S_{A L K}}{K_{A, A L K}+S_{A L K}} X_{A}$ \\
\hline 12 & Aerobic endog. Respiration of $X_{A}$ & $R_{12}=b_{A, O_{2}} \frac{S_{O_{2}}}{K_{A, O_{2}}+S_{O_{2}}} X_{A}$ \\
\hline 13 & Anoxic endog. Respiration of $X_{A}$ & $R_{13}=b_{A, N O_{X}} \frac{K_{A, O_{2}}}{K_{A, O_{2}}+S_{O_{2}}} \frac{S_{N O_{X}}}{K_{N O_{X}}+S_{N O_{X}}} X_{A}$ \\
\hline
\end{tabular}

\subsection{Model configuration}

Both modified and standard ASM3 were configured to be applied in a post-denitrification MBR process shown in Fig.1.

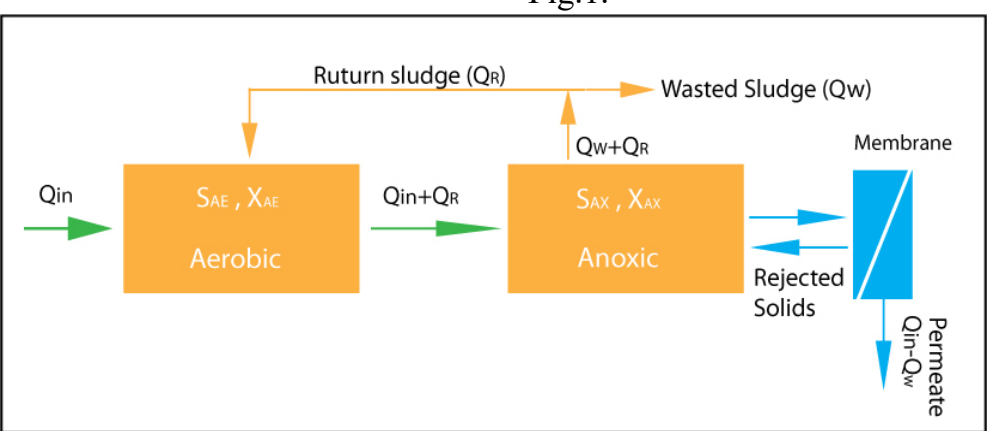

Fig.1. Plant configuration of a post-denitrification MBR

The average hydraulic retention time (HRT) for the whole plant was $12 \mathrm{~h}$. With the average influent flow rate of $18446 \mathrm{~m}^{3} / \mathrm{d}$ (Table.3), the total volume of aerobic $\left(V_{A E}\right)$ and anoxic tank $\left(V_{A X}\right)$ could be calculated to be $9223 \mathrm{~m}^{3}$. The $V_{A E} / V_{A X}$ ratio was chosen to be $50 / 50 \%$ [8]. The total SRT was set to be within 10-90 days by adjusting the wasted sludge flow rate $\left(Q_{W}\right)$. The return sludge flow rate $\left(Q_{R}\right)$ from anoxic tank to aerobic tank was set to be $50 \%$ of the average influent flow rate.
Table.3. The flow-weighted average influent concentration

\begin{tabular}{|c|c|}
\hline Symbol & Value \\
\hline$S_{I}$ & 30 \\
\hline$S_{S}$ & 69.5 \\
\hline$S_{N H 4}$ & 38.51 \\
\hline$S_{N O X}$ & 0 \\
\hline$S_{A L K}$ & 7 \\
\hline$X_{S H}\left(X_{I}\right)$ & 51.20 \\
\hline$X_{S}$ & 202.32 \\
\hline$X_{H}$ & 28.17 \\
\hline
\end{tabular}




\begin{tabular}{|c|c|}
\hline$X_{A}$ & 0 \\
\hline$X_{S T O}$ & 0 \\
\hline$Q$ & $18446 \mathrm{~m}^{3} / \mathrm{d}$ \\
\hline
\end{tabular}

The mass balance equation for the aerobic tank could be written by the following equations:

$$
\begin{aligned}
& V_{A E} \frac{d S_{A E}}{d t}=Q_{i n} S_{i n}+Q_{R} S_{A X}-\left(Q_{i n}+Q_{R}\right) S_{A E}+r_{A E}^{S} V_{A E} \\
& V_{A E} \frac{d X_{A E}}{d t}=Q_{i n} X_{i n}+Q_{R} X_{A X}-\left(Q_{i n}+Q_{R}\right) X_{A E}+r_{A E}^{X} V_{A E}
\end{aligned}
$$

Where, $S_{A E}, X_{A E}$ represent the soluble and solid component concentration in the aerobic tank; $r_{A E}^{S}$ and $r_{A E}^{X}$ were the reaction rate of the soluble and solid component respectively, which could be calculated from the stoichiometric matrix and kinetic rates in Table. 1 and Table.2.

Similarly, the mass balance equations for the anoxic tank were:

$$
\begin{aligned}
& V_{A X} \frac{d S_{A X}}{d t}=\left(Q_{i n}+Q_{R}\right)\left(S_{A E}-S_{A X}\right)+r_{A X}^{S} V_{A X} \\
& V_{A X} \frac{d X_{A X}}{d t}=\left(Q_{i n}+Q_{R}\right) X_{A E}-\left(Q_{R}+Q_{W}\right) X_{A X}+r_{A X}^{X} V_{A X}
\end{aligned}
$$

Where, $S_{A X}, X_{A X}$ represent the soluble and solid component concentration in the aerobic tank; $r_{A X}^{S}$ and $r_{A X}^{X}$ are the reaction rate of the soluble and solid component.

\subsection{Model implementation}

The "dry weather" influent data from the benchmark configuration was used to compare the modified ASM with the standard ASM3[9][10]. The benchmark influent data was available in 14 days with 15 minutes interval. The variation in influent flow rate and concentration (1) $\mathrm{S}_{\text {NOX }}$

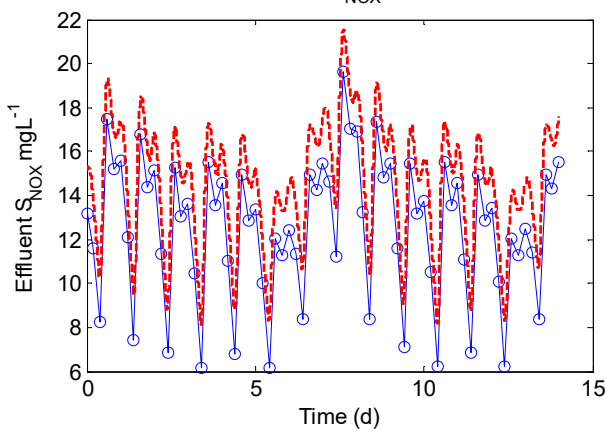

(3) $X_{H}$

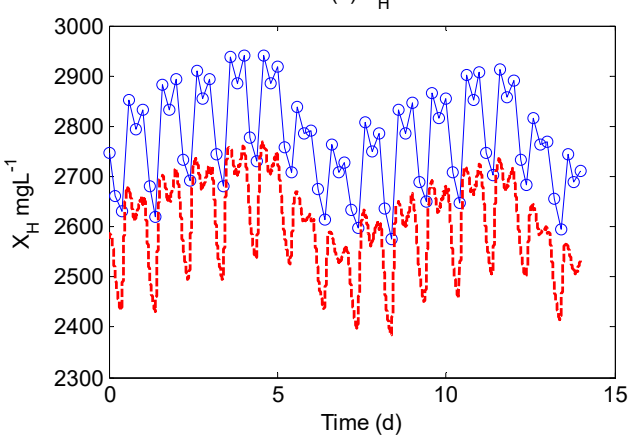

made the simulation in an unsteady condition. To eliminate the influence of initial conditions on the modeling results, the steady state was derived by simulating 100 days using the flow-weighted average influent data (Table.3). The steady state solved this way was regarded as the initial condition for the following dynamic modeling.

Since the influent file was made for the ASM1, some modifications were needed to use it in the ASM3 model. The soluble biodegradable nitrogen $\left(S_{N D}\right)$ in the benchmark data was included in the $\mathrm{NH}_{4}{ }^{+}\left(S_{N H}\right)$ as the ammonification process was assumed to be fast and removed in ASM3. The particulate biodegradable nitrogen $\left(X_{N D}\right)$ was omitted as it was included in other solids components.

\section{Modeling results}

\subsection{Comparison with no hydrolysis}

Fig.2 showed the comparison of nitrogen removal and solids concentration between the modified and standard ASM3 at SRT of $40 \mathrm{~d}$. With the hydrolysis of $X_{S H}$ included in the modified model, a lower $5.5 \mathrm{~g} / \mathrm{L} X_{S H}$ was predicted, as compared to the $7 \mathrm{~g} / \mathrm{L}$ for the standard ASM3. Correspondingly, the $S_{N O X}$ concentration in the modified ASM3 prediction was lower than the standard ASM3, suggesting higher denitrification efficiency due to the extra carbon source from the $X_{S H}$ hydrolysis. The carbon storage $\left(X_{S T O}\right)$ and heterotrophic biomass concentration $\left(X_{H}\right)$ are also higher in the modified ASM3 prediction than the standard ASM3 prediction.
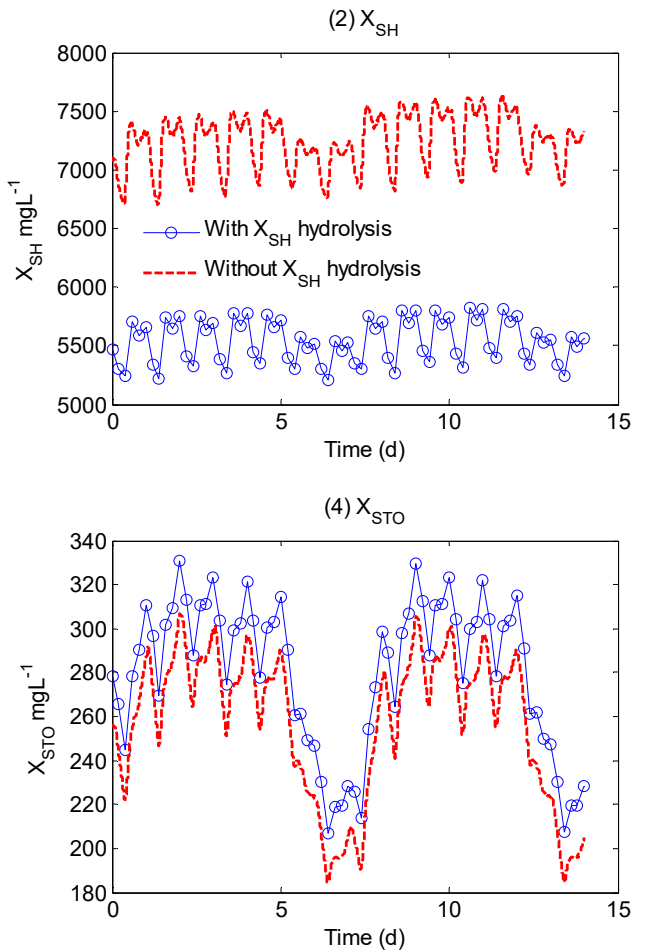

Fig.2. Comparison of nitrogen removal and solids concentration between the modified and standard ASM3. 


\subsection{Effect of SRT on the availability of carbon source for denitrification}

The carbon source used for de-nitrification in the ASM3 framework was assumed from the consumption of carbon storage $\left(X_{S T O}\right)$. The anoxic growth of heterotrophic biomass $\left(X_{H}\right)$ on the carbon storage $\left(X_{S T O}\right)$ results in the denitrification of $S_{N O X}$. The total carbon source consumed for denitrification $\left(C_{X_{s o} \rightarrow D}, \mathrm{mg} / \mathrm{L}\right)$ in the 14 days simulation can be calculated from the following equation:

$$
C_{X_{S t o} \rightarrow D}=\int_{0}^{14} \frac{R_{6}}{Y_{H, N O X}} d t
$$

Where, $R_{6}\left(\mathrm{mgL}^{-1} \mathrm{~d}^{-1}\right)$ was the heterotrophic biomass $\left(X_{H}\right)$ anoxic growth rate (Table.2); $Y_{H, N O X}$ was the anoxic yield of heterotrophic biomass $\left(X_{H}\right)$.

The percentage of extra carbon source used for denitrification due to hydrolysis of $X_{S H}$ can be calculated

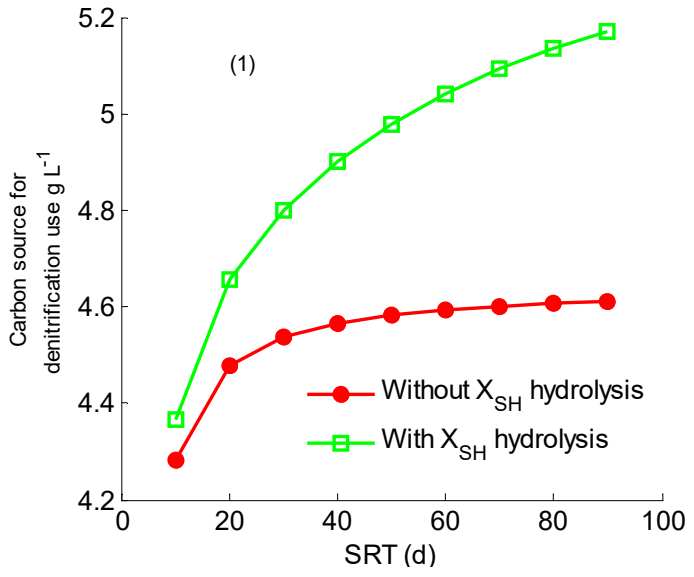

by:

$$
P_{S H}=\frac{C_{X_{s t o} \rightarrow D}^{h}-C_{X_{s t} \rightarrow D}^{n h}}{C_{X_{s o} \rightarrow D}^{h}} 100 \%
$$

Where, $C_{X_{s t} \rightarrow D}^{h}$ was the total carbon source consumed for denitrification calculated from equation 0 , including the $X_{S H}$ hydrolysis process; $C_{X_{s o}^{n h} \rightarrow D}^{n h}$ was the equivalent without the $X_{S H}$ hydrolysis process.

Fig.3(1) showed that the amount of carbon source used for denitrification $\left(C_{X_{s o} \rightarrow D}\right)$ increased with SRT. The increasing scope was much higher when the hydrolysis of $X_{S H}$ was included. Without the carbon source from the hydrolysis of $X_{S H}$, the $C_{X_{s t o} \rightarrow D}$ value maintained around $4.6 \mathrm{~g} / \mathrm{L}$ when the SRT was between 50-90 days. Fig.3(2) indicated that an extra of $2-10 \%$ of carbon source was used in denitrification due to the hydrolysis of $X_{S H}$.

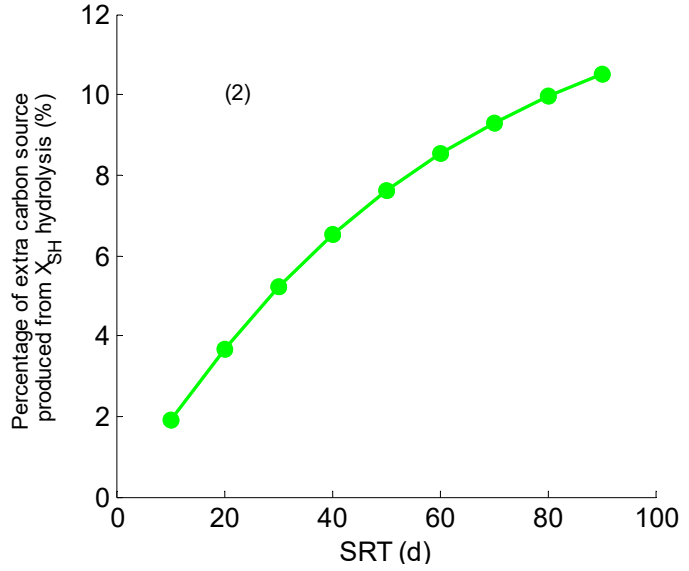

Fig.3. Carbon source used for denitrification under different SRT

\subsection{Sludge production under different SRT}

The standard ASM developed for CAS used in long SRT MBR overestimated the sludge production[3]. By including a hydrolysis process for the slowly hydrolysable $X_{S H}$, Lubello et al.[5] reported satisfactory sludge production estimation with hydrolysis kinetic rate $K_{S H}$ of $0.012 \mathrm{~d}^{-1}$. Fig.4(1) showed that the modified ASM3 predicted a significant lower sludge production compared

(1)

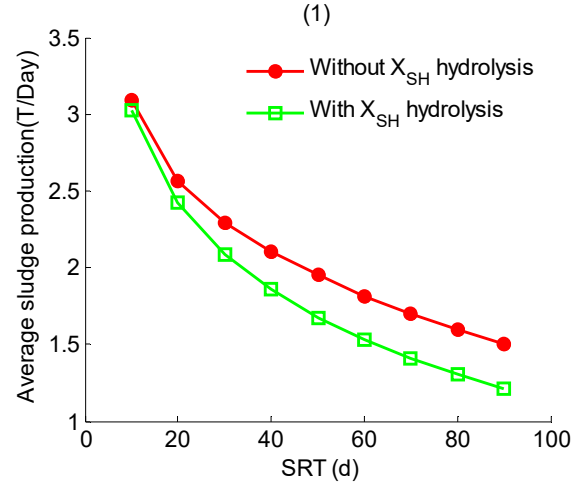

to the standard ASM3. Pollice et al.[11]reported sludge production of a MBR treating municipal wastewater at SRT of 20, 40, 60 and $80 \mathrm{~d}$. By normalizing the sludge production to the $\mathrm{SRT}=20 \mathrm{~d}$ value and comparing to the predicted sludge production by the modified and standard ASM3 (Fig.4(2)), it could be found that the modified ASM3 showed a better match to the Pollice's[11] sludge production data. This suggested that the $K_{S H}$ value of $0.012 \mathrm{~d}^{-1}$ might be meaningful.

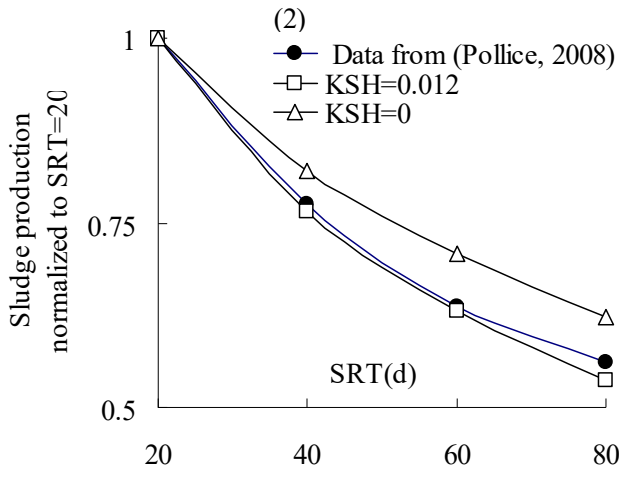

Fig.4. Sludge production under different SRT 


\subsection{Effect of hydrolysis rate on the model prediction results}

It should be noted that the $K_{S H}$ value of $0.012 \mathrm{~d}^{-1}$ from Lubello et al.[5]was derived from experiment on tannery wastewater. It might not be the same for domestic sewage. Fig.5 showed the effluent $S_{N O X}$ and $X_{S H}$ in the mixed liquor prediction by the modified ASM3 under different $K_{S H}$ value. It can be seen that de-nitrification efficiency was greater for high value and a significant low $X_{S H}$ was predicted.

Fig. 5 was derived by simulating the modified ASM3 model under different $K_{S H}$ value with other parameters kept the same. Some of the parameters for the long SRT MBR configuration might need to be altered, which might contradict or further enhance the trend shown in Fig.5. More experiment validation of the modified ASM3 is needed.
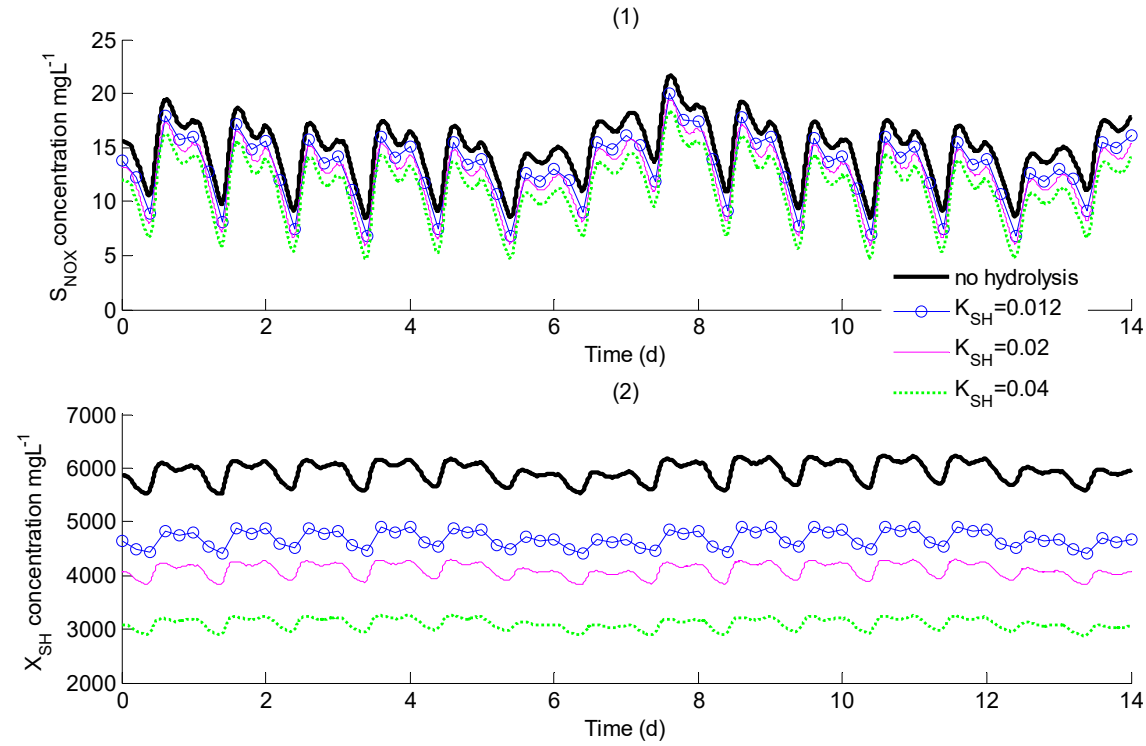

Fig.5. Effect of hydrolysis rate on the model prediction results

\section{Conclusion}

A modified ASM3 model was proposed that included the hydrolysis of previously assumed "inert" organics. The simulation of the modified ASM3 model on post-denitrification MBR indicated that more carbon source was available for denitrification from the hydrolysis of $X_{S H}$. A lower sludge production was also predicted by the modified ASM3 model.

\section{References:}

1. M.Henze, et al., Activated Sludge Models ASM1, $A S M 2, A S M 2 d$, and ASM3. IWA Scientific and Technical Report No. 9.IWA Publishing, London, UK. (2000)

2. S. Judd, The MBR Book, Oxford. Elsevier Science (2006)

3. A.Fenu, et al., Water Res., 44(15),4272-4294 (2010)

4. G.A.Ekama, P.L. Dold, and G.v.R. Marais, Wat. Sci. Tech.,18(6),91-114 (1986)

5. C.Lubello, et al., Water Res.,43(18),4539-4548(2009)

6. M.Vocks, et al., Water Res., 39(14),3360-3368(2005)

7. M.Winkler, E.R. Coats, and C.K. Brinkman, Water Res., 45(18),6119-6130 (2011)
8. J.Pinnekamp, Municipal Water and Waste Management:Membrane Technology for Waste Water Treatment. FIW Verlag, Aachen (2006)

9. J.B.Copp, The COST Simulation Benchmark: Description and Simulator Manual.Office for Official Publications of the European Communities, Luxembourg (2002)

10. I.Iacopozzi, et al., Environ. Model. Softw., 22(6),847-861 (2007)

11. A.Pollice, Laera, G., Saturno, D., Giordano, C, J. Membr. Sci., 317(1-2), 65-70 (2008) 